\title{
RESEARCH
}

Open Access

\section{Plasma transferrin and hemopexin are associated with altered $A \beta$ uptake and cognitive decline in Alzheimer's disease pathology}

Azhaar Ashraf ${ }^{1}$, Nicholas J. Ashton 2,3,4,5, Pratishtha Chatterjee ${ }^{6,7,8}$, Kathryn Goozee ${ }^{7,8,9,10}$, Kaikai Shen ${ }^{11,12}$, Jurgen Fripp ${ }^{12}$, David Ames ${ }^{13,14}$, Christopher Rowe ${ }^{15}$, Colin L. Masters ${ }^{16}$, Victor Villemagne ${ }^{15}$, Abdul Hye ${ }^{2,3+}$, Ralph N. Martins ${ }^{6,7,8^{*}+}$, Po-Wah So ${ }^{1 * \dagger}$ (D) and AIBL

\begin{abstract}
Background: Heme and iron homeostasis is perturbed in Alzheimer's disease (AD); therefore, the aim of the study was to examine the levels and association of heme with iron-binding plasma proteins in cognitively normal (CN), mild cognitive impairment $(\mathrm{MCl})$, and $\mathrm{AD}$ individuals from the Australian Imaging, Biomarker and Lifestyle Flagship Study of Ageing (AIBL) and Kerr Anglican Retirement Village Initiative in Ageing Health (KARVIAH) cohorts.

Methods: Non-targeted proteomic analysis by high-resolution mass spectrometry was performed to quantify relative protein abundances in plasma samples from $144 \mathrm{CN}$ individuals from the AIBL and $94 \mathrm{CN}$ from KARVIAH cohorts and $21 \mathrm{MCl}$ and $25 \mathrm{AD}$ from AIBL cohort. ANCOVA models were utilized to assess the differences in plasma proteins implicated in heme/iron metabolism, while multiple regression modeling (and partial correlation) was performed to examine the association between heme and iron proteins, structural neuroimaging, and cognitive measures.
\end{abstract}

Results: Of the plasma proteins implicated in iron and heme metabolism, hemoglobin subunit $\beta(p=0.001)$ was significantly increased in AD compared to CN individuals. Multiple regression modeling adjusted for age, sex, APOE 44 genotype, and disease status in the AIBL cohort revealed lower levels of transferrin but higher levels of hemopexin associated with augmented brain amyloid deposition. Meanwhile, transferrin was positively associated with hippocampal volume and MMSE performance, and hemopexin was negatively associated with CDR scores. Partial correlation analysis revealed lack of significant associations between heme/iron proteins in the $\mathrm{CN}$ individuals progressing to cognitive impairment.

Conclusions: In conclusion, heme and iron dyshomeostasis appears to be a feature of AD. The causal relationship between heme/iron metabolism and AD warrants further investigation.

Keywords: Alzheimer's disease, Cognitively normal, Cognitive impairment, Heme, Hemoglobin, Iron, Mild cognitive impairment, Proteomics, Transferrin

\footnotetext{
* Correspondence: ralph.martins@mq.edu.au; po-wah.so@kcl.ac.uk

${ }^{+}$Abdul Hye, Ralph N. Martins, and Po-Wah So are joint senior authors

${ }^{6}$ School of Medical Sciences, Edith Cowan University, 270, Joondalup, WA 6027, Australia

'Department of Neuroimaging, Institute of Psychiatry, Psychology and Neuroscience, Maurice Wohl Clinical Neuroscience Institute, King's College London, 5, Cutcombe Road, Denmark Hill Campus, London SE5 9RX, UK

Full list of author information is available at the end of the article
}

(c) The Author(s). 2020 Open Access This article is licensed under a Creative Commons Attribution 4.0 International License, which permits use, sharing, adaptation, distribution and reproduction in any medium or format, as long as you give appropriate credit to the original author(s) and the source, provide a link to the Creative Commons licence, and indicate if changes were made. The images or other third party material in this article are included in the article's Creative Commons licence, unless indicated otherwise in a credit line to the material. If material is not included in the article's Creative Commons licence and your intended use is not permitted by statutory regulation or exceeds the permitted use, you will need to obtain permission directly from the copyright holder. To view a copy of this licence, visit http://creativecommons.org/licenses/by/4.0/ The Creative Commons Public Domain Dedication waiver (http://creativecommons.org/publicdomain/zero/1.0/) applies to the data made available in this article, unless otherwise stated in a credit line to the data. 


\section{Background}

Alzheimer's disease (AD) is the most common cause of dementia in the elderly population, with an estimated prevalence of 115.4 million cases by 2050 [1]. AD is a heterogenous disorder characterized clinically by apraxia, aphasia, and agnosia and neuropathologically by the presence of $\beta$-amyloid plaques and hyperphosphorylated tau tangles $[2,3]$. Regional measures of hippocampal atrophy have been identified as strong predictors of progression to $\mathrm{AD}$ [4]. Emerging evidence suggests that brain and blood iron homeostasis is perturbed in $\mathrm{AD}$, with studies showing decreased peripheral iron (anemia) and lower hemoglobin levels [5-11]. Anemia is a prevalent condition in the elderly and is associated with an increased risk of acquiring $\mathrm{AD}[7,8,12,13]$.

Evidence suggests that hemoglobin $(\mathrm{Hb})$, a group of iron-containing heme proteins, is not exclusively restricted to the blood but likely play a role in pathophysiology of the brain and neurodegenerative diseases [14]. $\mathrm{Hb}$ acts likely as an oxygen storage molecule to counteract hypoxic effects on neurons, which have high obligate demand for sustained energy [14, 15]. $\mathrm{Hb}$ is expressed throughout the brain including the striatum, corpus callosum, and brainstem $[14,15]$. High levels of Hb components are evident in brains of older humans and rats [16], associated with impaired learning and memory [17]. $\mathrm{Hb}$ interacts with $\beta$-amyloid $(A ß)$ and co-localizes with $A ß$ plaques in $A D$ post-mortem brains [18, 19]. Importantly, $\mathrm{Hb}$ levels were augmented in amyloid pathologyassociated brain regions-inferior temporal gyrus, cerebral parietal gray matter, and parietal white matter [19]. The association between brain region-specific $\mathrm{Hb}$ levels and $A \beta$ pathology in $A D$ patients suggests a link between $\mathrm{Hb}$ expression and $\mathrm{AD}$ pathogenesis.

Although research evaluating the differences between individual subunits of $\mathrm{Hb}$ remains sparse, there is evidence that specific subunits have varying properties and functions. Studies of blood from healthy humans show that $\mathrm{Hb \alpha}$ subunits efficiently scavenge hydrogen peroxide to prevent oxidative degradation of $\mathrm{Hb}$ [20]. $\mathrm{Hb \alpha}$ positive neurons, juxtaposing $\mathrm{Hb} \alpha$-negative neurons, have higher oxygenation potential in hypoxic areas in the mouse brain under normoxic and hypoxic conditions [21]. Interestingly, $\mathrm{Hb \alpha}$ levels were predominantly decreased in brain synaptosomes in a transgenic rat model of $\mathrm{AD}$ [22]. Meanwhile, $\mathrm{Hb} \beta$-enriched neurons are frequent in internal cortical layers IV-VI relative to external layers I-III; most of these neurons had pyramidal morphology with large size, apical dendrites, and long axons [23]. It was found that overexpression of $\mathrm{Hb} \beta$ but not $\mathrm{Hb} \alpha$ epigenetically increased histone $\mathrm{H} 3$ methylation to sequester oxygen from histone demethylases [23]. Although the $\alpha$ and $\beta$ subunits of $\mathrm{Hb}$ function as a heterotetramer in erythrocytes, these proteins have putatively evolved specialized functions and may act independent of one another in selected cells. This proposition is further supported by the expression of $\mathrm{Hb \alpha}$ in vascular endothelial cells where it regulates nitric oxide signaling, independent of $\mathrm{Hb} \beta$ [24].

In neurons laden with hyperphosphorylated tau deposits, appreciable decreases in $\mathrm{Hb}$ subunits $\alpha$ and $\beta$ were evident in the frontal cortex and hippocampus in $\mathrm{AD}$ [25]. Analysis of samples from the CSF showed higher $\mathrm{Hb} \alpha$ and $\mathrm{Hb} \beta$ which could differentiate between AD converters from non-converters in individuals with mild cognitive impairment (MCI) [26]. However, Hb subunits did not yield significant differences between $\mathrm{CN}, \mathrm{MCI}$, and $\mathrm{AD}$. This suggests that $\mathrm{Hb}$ subunits may show an initial increase in response to $\mathrm{AD}$ pathology but due to ongoing disease, $\mathrm{Hb}$ may leak from degenerating neurons into CSF and explain the augmented CSF levels in $\mathrm{MCI}$ converting to $\mathrm{AD}$. Note that a stringent protocol was implemented to avoid blood contamination to ensure removal of plasma proteins from CSF samples to assure robustness of results [26]. The role of another $\mathrm{Hb}$ subunit, $\mathrm{Hb} \delta$, in aging and disease has not been investigated. Hb $\delta$ genes show homology to $\mathrm{Hb} \beta$ [15]; hence, it can be hypothesized to follow similar changes to $\mathrm{Hb} \beta$ in the context of $\mathrm{AD}$.

$\mathrm{Hb}$ oxidation liberates free heme, a source of redoxactive iron, which produces reactive oxygen species through Fenton reaction, inducing lipid peroxidation [27]. This toxicity is modulated by hemopexin (HPX) and haptoglobin, proteins which bind heme with high affinity to maintain iron homeostasis through recycling of heme iron $[28,29]$. Proteomics studies demonstrated increased plasma and CSF HPX in AD patients compared to cognitively normal $(\mathrm{CN})$ subjects, suggesting impaired compensation in neurodegeneration [30,31]. It appears that surplus contribution to heme by breakdown of $\mathrm{Hb}$ may overwhelm the capacity of the heme scavenging system in AD [28, 32-34].

Systemic deficits in iron trafficking can contribute to morbidity associated with $\mathrm{AD}$, since iron acts as a catalyst for a plethora of metabolic processes, including heme formation, neurotransmitter synthesis, and axonal myelination [7, 8]. Deficiency of iron loading onto its major transporter protein, transferrin, was observed in $\mathrm{AD}[8]$, which suggests further examination of peripheral iron/heme metabolism.

Since AD represents a global disease burden, plasma proteins have been extensively associated with progression of the disease [35]. The present study investigated the levels of plasma proteins involved in heme and iron homeostasis in cognitively normal $(\mathrm{CN}), \mathrm{MCI}$, and $\mathrm{AD}$ individuals. The uniqueness of the study was that it identified $\mathrm{CN}$ individuals who either remained stable or showed progression to cognitive impairment and examined retrospectively their baseline plasma proteins and 
association to $\mathrm{AD}$ markers. The baseline expression levels of plasma hemoglobin $(\mathrm{Hb})$ subunits $(\alpha, \beta$, and $\delta)$ and their association to AD markers have not been previously documented, highlighting the importance of the present study. Based on the evidence reviewed, we hypothesize that $\mathrm{Hb} \beta$ would be associated with higher A $\beta$ deposition, hippocampal atrophy, and cognitive decline. We also predict that higher levels of $\mathrm{Hb \alpha}$, hemopexin, and transferrin will be associated with lower $A \beta$ deposition, improved hippocampal volumes, and improved cognitive performance.

\section{Methods}

\section{Participants}

The dataset comprised $144 \mathrm{CN}, 21 \mathrm{MCI}$, and $25 \mathrm{AD}$ individuals derived from the Australian Imaging, Biomarker and Lifestyle Flagship Study of Ageing (AIBL $[11,36,37])$ and $94 \mathrm{CN}$ from Kerr Anglican Retirement Village Initiative in Ageing Health (KARVIAH) cohort [38]. The AIBL cohort underwent baseline A $\beta$ PET imaging $\left({ }^{11} \mathrm{C}\right.$-PIB) [37], while KARVIAH cohort had baseline ${ }^{18}$ F-FBB (florbetaben) amyloid PET imaging [11]. Only the AIBL individuals included in the study received magnetic resonance imaging (MRI) using the ADNI three-dimensional magnetization prepared rapid gradient echo (MPRAGE) sequence, with the following parameters: $1 \times 1 \mathrm{~mm}$ in-plane resolution, $1.2 \mathrm{~mm}$ slice thickness, field of view $240 \times 256,160$ slices, repetition time $(\mathrm{TR})=2300 \mathrm{~ms}$, echo time $(\mathrm{TE})=2.98 \mathrm{~ms}$, inversion time $(\mathrm{TI})=900 \mathrm{~ms}$, and flip angle $9^{\circ}$. T2-weighted fast spin echo (FSE) and fluid attenuation inversion recovery (FLAIR) sequences were also applied [37]. MRI-based measures of hippocampal, gray matter, and white matter volumes were derived.

AIBL and KARVIAH subjects had mini-mental state examination (MMSE) [11, 37], while clinical dementia rating scale (CDR) and sum of boxes (CDR SB) were computed for the AIBL cohort [37].

\section{Inclusion and exclusion criteria for KARVIAH}

Participants with good health and no history of significant cerebral vascular disease, fluent in English, with adequate vision and hearing to enable testing, and with normal general cognitive function as determined by Montreal Cognitive Assessment (MoCA) [39] scores greater than or equal to 26 were included. The exclusion criteria included diagnosis of dementia based on the revised criteria from the National Institute on Aging - Alzheimer's Association, presence of acute functional psychiatric disorder (including lifetime history of schizophrenia or bipolar disorder), history of stroke, and presenting with depression based on the Depression, Anxiety, Stress Scales (DASS) and uncontrolled hypertension (systolic BP $>170$ or diastolic $\mathrm{BP}>100$ ).

\section{Inclusion and exclusion criteria for AIBL}

$\mathrm{CN}$ individuals were free of cognitive impairment, while MCI was defined as a clinical syndrome characterized by reduced cognitive performance (often involving memory), representing a risk state for development of frank $\mathrm{AD}[40,41]$. The diagnosis of $\mathrm{AD}$ was made according to the National Institute of Neurological and Communicative Disorders and Stroke - Alzheimer's Disease and Related Disorders Association (NINCDS-ADRDA) criteria [42]. Allocation of individuals to $\mathrm{CN}, \mathrm{MCI}$, or $\mathrm{AD}$ was undertaken by a clinical review panel (see below). When individuals presented with an existing diagnosis of $\mathrm{MCI}$ or $\mathrm{AD}$, the diagnosis was established by a clinical review panel to ensure that diagnoses were made according to internationally agreed criteria. Potential participants were excluded if they had a history of non-AD dementia, schizophrenia, bipolar disorder, significant depression (GDS score $>5 / 15$ ), Parkinson's disease, cancer within last 2 years, stroke, or uncontrolled diabetes.

Dementia severity was rated for all participants with $\mathrm{CDR}=0,0.5,1,2$, or 3 when dementia is absent, questionable, mild, moderate, or severe, respectively [43]. Since six domain scores ranging from 0 to 3 are generated for CDR, a sum of boxes score is also calculated ranging from 0 to 18 .

Individuals that participated as $\mathrm{CN}$ at baseline in the AIBL trial were discussed by a clinical review panel (comprising neurologists, old age psychiatrists, geriatricians, and neuropsychologists). For individuals with an MMSE score $<28$, failure on the logical memory test (as per ADNI guidelines, http://adni.loni.usc.edu/), and/or a CDR score $\geq 0.5$ [36], a consensus diagnosis was assigned based on diagnostic criteria DSM-IV [44] and ICD-10 [45] and whether the subject violated the exclusion criteria. $\mathrm{CN}$ individuals who progressed to fulfill MCI diagnosis according to established Winblad et al. [41] and Petersen et al. criteria [40] had to also have impairment on two or more cognitive tests at a level of at least 1.5 standard deviation below age-adjusted mean, in addition to have reported memory difficulties. Individuals were assigned a diagnosis of probable AD if they reported deficits in multiple cognitive domains and impairment in activities of daily living sufficient to satisfy NINCDS-ADRDA [42], DSM-IV [44], and ICD-10 [45] criteria.

\section{Mass spectrometry analysis}

The methodology used in this study has been previously described [38]. In brief, AIBL and KARVIAH plasma samples were immuno-depleted of albumin and IgG, and then enzymatically digested prior to tandem mass tag (TMT) labeling. The resulting peptides were separated into 24-fractions by an OFFGEL Fractionator (Agilent Technologies) and individually analyzed by a Linear Trap Quadrupole (LTQ) Orbitrap Velos Pro (Thermo 
Fisher Scientific), enabling chromatographic separation and mass spectra acquisition.

\section{Statistical analyses}

Proteins involved in iron and heme metabolism were selected from a panel of plasma proteins [38] and analyzed, which included transferrin, ceruloplasmin, hemopexin, haptoglobin, haptoglobin-related protein (HPR), Hb subunits $(\alpha, \beta, \delta)$, cluster of differentiation 163 (CD163), and low-density lipoprotein receptor-related protein (LRP1). ANCOVA models were used to compare the baseline levels of plasma proteins, neuroimaging, and cognition measures between the diagnostic groups $(\mathrm{CN}, \mathrm{MCI}$, and $\mathrm{AD}$ ), adjusted for age, sex, $\mathrm{APOE} \varepsilon 4$ genotype, and disease status. Multiple regression models were utilized to study the association of plasma proteins with neuroimaging measures and cognitive assessments, where minimal models were obtained using backward elimination.

Subsequently, the CN subset from the AIBL cohort was dichotomized into individuals that progressed to show symptoms of cognitive impairment and individuals that remained stable, 6 years later. ANCOVA and linear regression analysis was performed as described above but the models were adjusted for age, sex, APOE $\varepsilon 4$ genotype, and conversion status. To delineate the association of proteins involved in iron and heme metabolism, partial correlation analysis was executed, adjusting for age, sex, and APOE\&4 genotype in $\mathrm{CN}$ individuals who remained stable and in individuals progressing to cognitive impairment.

To correct for multiple comparisons, we used an adaptive linear set-up procedure proposed by Benjamini et al. [46] to control the false discovery rate (FDR) at 5\% across all the analyses. An FDR-corrected $p$ value $\leq$ 0.0167 was considered significant. All statistical analyses were performed using IBM SPSS Statistics 24 and GraphPad Prism 8.4.2.

\section{Results}

Baseline levels of plasma heme and iron proteins in $\mathrm{CN}$, $\mathrm{MCl}$, and $\mathrm{AD}$

The baseline demographic and clinical characteristics of the different diagnostic groups are presented in Table 1. AD subjects exhibited increased brain amyloid deposition compared to $\mathrm{CN}$ and $\mathrm{MCI}$, while $\mathrm{MCI}$ had higher brain amyloid deposition than $\mathrm{CN}\left(p=3.224 \times 10^{-20}\right)$. The right $(p=0.008)$ and left hippocampal $(p=3.600 \times$ $10^{-5}$ ) volumes were found to be markedly reduced in $A D$ relative to $C N$. Individuals with $A D$ had lower MMSE scores and increased CDR and sum of boxes compared to $\mathrm{CN}$ and $\mathrm{MCI}$, while the MCI group performed worse on MMSE $\left(p=9.453 \times 10^{-54}\right)$ and had higher $\operatorname{CDR}\left(p=9.139 \times 10^{-56}\right)$ and sum of boxes $(p=$ $3.384 \times 10^{-73}$ ) compared to $\mathrm{CN}$.
Of the plasma proteins implicated in iron and heme metabolism, $\mathrm{Hb} \beta$ subunit $(p=0.001)$ was significantly increased at baseline in $\mathrm{AD}$ compared to $\mathrm{CN}$ individuals (Table 2).

\section{Relationship between baseline plasma proteins and} neuroimaging/cognitive measures in $\mathrm{CN}, \mathrm{MCl}$, and $\mathrm{AD}$ Multiple regression modeling of brain amyloid deposition (assessed by PET) revealed lower levels of transferrin $(\beta=-0.206, p=0.008)$ and a trend of lower $\mathrm{Hb \alpha}$ $(\beta=-0.194, p=0.060$, not significant), but higher HPX levels $(\beta=0.215, p=0.007)$ and a trend of increased $\mathrm{Hb} \delta$ $(\beta=0.186, p=0.073$, not significant) were associated with augmented brain amyloid deposition (Fig. 1a). Higher levels of transferrin were associated with larger gray matter volume $(\beta=0.178, p=0.005$; Fig. $1 b)$ and non-significant improvements in MMSE scores $(\beta=$ 0.077, $p=0.097$; Fig. 1c). Higher levels of hemopexin were associated with lower CDR scores that failed to reach significance $(\beta=-0.064, p=0.081$; Fig. 1d).

\section{Baseline levels of brain amyloid deposition, cognition, and plasma proteins in $\mathrm{CN}$ individuals}

$\mathrm{CN}$ individuals from the AIBL cohort stratified according to their conversion status (Table 3) demonstrated elevated brain amyloid deposition in individuals exhibiting progression to cognitive impairment compared to stable CN subjects $(p=0.008)$, while MMSE scores were lower in the former $(p=0.006)$. No significant alterations in the plasma iron or heme proteins were observed in individuals remaining stable or showing disease progression (Table 4).

\section{Relationship between plasma proteins and neuroimaging/ cognitive measures in $\mathrm{CN}$ individuals}

Multiple regression modeling of brain amyloid deposition in $\mathrm{CN}$ subjects demonstrated lower levels of transferrin $(\beta=-0.324, p=0.0003)$ and ceruloplasmin $(\beta=-0.142$, $p=0.067)$, but higher levels of HPX $(\beta=0.408, p=3.34 \times$ $10^{-4}$ ) were associated with increased amyloid deposition (Fig. 2a). The left hippocampal volume was negatively correlated to ceruloplasmin $(\beta=-0.167, p=0.052)$ and $\mathrm{Hb} \beta$ $(\beta=-0.277, p=0.051)$ but positively correlated to hemopexin $(\beta=0.143, p=0.087)$ and $\mathrm{Hb} \alpha(\beta=0.271, p=0.059)$, but failed to reach significance (Fig. 2b). Meanwhile, higher levels of transferrin $(\beta=0.145, p=0.042)$ and $\mathrm{Hb} \alpha$ $(\beta=0.217, p=0.098)$ but lower levels of $\operatorname{Hb} \beta(\beta=-0.242$, $p=0.065)$ were associated with a larger gray matter volume (Fig. 2c), which did not yield significance. Linear regression modeling with MMSE score as the dependent variable in $\mathrm{CN}$ subjects revealed augmented levels of transferrin $(\beta=0.312, p=0.010)$ associated with better performance on the MMSE (Fig. 3a). Lastly, hemopexin was negatively correlated to the CDR score $(\beta=-0.202$, $p=0.016$; Fig. $3 \mathrm{~b})$ and CDR sum of boxes $(\beta=-0.198$, 
Table 1 Baseline demographic and clinical characteristics of $\mathrm{CN}, \mathrm{MCl}$, and $\mathrm{AD}$ subjects

\begin{tabular}{|c|c|c|c|c|c|}
\hline & & $\mathrm{CN}$ & $\mathrm{MCl}$ & $A D$ & $p$ value \\
\hline$n$ & - & $144 \mathrm{AIBL}, 94 \mathrm{KARVIAH}$ & 21 & 25 & NA \\
\hline Age & Years (s.d.) & $75(7.362)$ & $75(6.226)$ & $71(9.072)$ & 0.170 \\
\hline Female & $n(\%)$ & $105(44 \%)$ & $9(43 \%)$ & $13(52 \%)$ & 0.743 \\
\hline APOE- $\varepsilon 4+v e$ & $n(\%)$ & $75(32 \%)$ & $10(48 \%)$ & $18^{\mathbf{b}}(72 \%)$ & $1.46 \times 10^{-4}$ \\
\hline PIB-PET $^{\#}$ & SUVR (s.d.) & $1.425(0.033)$ & $1.853^{\mathbf{a}}(0.089)$ & $2.374^{\mathbf{b}, \mathbf{c}}(0.086)$ & $3.224 \times 10^{-20}$ \\
\hline MRI hippocampus (right, $\left.\mathrm{cm}^{3}\right)^{\#}$ & Mean (s.d.) & $3.102(0.030)$ & $2.970(0.106)$ & $2.858^{\mathbf{b}}(0.107)$ & 0.008 \\
\hline MRI hippocampus (left, $\left.\mathrm{cm}^{3}\right)^{\#}$ & Mean (s.d.) & $3.200(0.031)$ & $3.142(0.108)$ & $3.075^{\mathbf{b}}(0.109)$ & $3.600 \times 10^{-5}$ \\
\hline MRI gray matter $\left(\mathrm{cm}^{3}\right)^{\#}$ & Mean (s.d.) & $671(4.611)$ & $694(16.207)$ & $633^{\mathbf{b}, \mathbf{c}}(16.316)$ & 0.029 \\
\hline MRI white matter ${ }^{\#}\left(\mathrm{~cm}^{3}\right)$ & Mean (s.d.) & 437 (4.514) & $438(15.866)$ & 449 (15.973) & 0.660 \\
\hline MMSE & Mean (s.d.) & $28.592(0.119)$ & $27.027^{\mathrm{a}}(0.388)$ & $20.686^{\mathbf{b}, \mathbf{c}}(0.382)$ & $9.453 \times 10^{-54}$ \\
\hline CDR scores $^{\#}$ & Mean (s.d.) & $0.027(0.013)$ & $0.493^{\mathbf{a}}(0.036)$ & $0.827^{\mathbf{b}, \mathbf{c}}(0.035)$ & $9.139 \times 10^{-56}$ \\
\hline CDR sum of boxes ${ }^{\#}$ & Mean (s.d.) & $0.039(0.045)$ & $1.325^{\mathbf{a}}(0.134)$ & $4.163^{\mathbf{b}, \mathbf{c}}(0.125)$ & $3.384 \times 10^{-73}$ \\
\hline
\end{tabular}

ANCOVA models adjusted for age, sex, and APOE\&4 genotype. The mean and standard deviation (s.d.) are presented in the table with false discovery rate correction set at $5 \%$

${ }^{\mathrm{a}} \mathrm{CN}$ vs $\mathrm{MCl}$

${ }^{b} \mathrm{CN}$ vs $A D$

${ }^{c} \mathrm{MCl}$ vs $A D$

${ }^{\#} \mathrm{AIBL}$ group only

$p=0.018$; Fig. 3c). However, the latter did not pass the FDR-corrected $p$ value threshold for significance.

\section{Association between heme and iron proteins in $\mathrm{CN}$ stable and progression groups}

To explain the differences in association between heme and iron proteins, partial correlation analysis was performed and illustrated as a heatmap with different association profiles in $\mathrm{CN}$ subjects remaining stable and those progressing to become cognitively impaired (Fig. 4). In the stable population, higher levels of ceruloplasmin were associated with elevated levels of $\operatorname{HPR}\left(r=0.422, p=3.523 \times 10^{-6}\right)$, Hbo $(r=$
$0.245, p=0.008), \mathrm{Hb} \beta \quad(r=0.191, p=0.044$, did not reach FDR-corrected significance), and hemopexin $\left(r=0.380, p=3.502 \times 10^{-5}\right)$, but this pattern of association was absent in the progression group. Also, ceruloplasmin was positively associated with haptoglobin in the stable group $(r=0.222, p=0.019)$ but did not pass the FDR-corrected significance threshold. Further, transferrin was positively associated with haptoglobin $\left(r=0.454, p=4.939 \times 10^{-7}\right)$ and HPR $(r=0.467$, $\left.p=2.156 \times 10^{-7}\right)$ in the stable group but not significant in the progression cohort. In the progression group, transferrin was negatively correlated to $\mathrm{Hb} \delta$ but did not reach significance $(r=-0.440, p=0.052)$.

Table 2 Baseline levels of plasma proteins involved in iron and heme metabolism in $\mathrm{CN}, \mathrm{MCl}$, and $\mathrm{AD}$ individuals

\begin{tabular}{llllll}
\hline Plasma proteins & & CN & MCl & AD & $p$ value \\
\hline Ceruloplasmin & Mean (s.d.) & $-0.001(0.004)$ & $0.002(0.013)$ & $0.003(0.012)$ & 0.867 \\
Transferrin & Mean (s.d.) & $0.000(0.006)$ & $-0.008(0.019)$ & $0.003(0.0170$ & 0.698 \\
Haptoglobin & Mean (s.d.) & $0.003(0.007)$ & $-0.025(0.025)$ & $-0.007(0.023)$ & 0.551 \\
Haptoglobin-related protein & Mean (s.d.) & $0.002(0.008)$ & $-0.019(0.027)$ & $-0.007(0.024)$ & 0.787 \\
Hemopexin & Mean (s.d.) & $-0.003(0.006)$ & $-0.016(0.020)$ & $0.037(0.018)$ & 0.059 \\
Hemoglobin alpha 1 subunit & Mean (s.d.) & $-0.009(0.012)$ & $-0.019(0.039)$ & $0.078(0.036)$ & 0.103 \\
Hemoglobin beta subunit & Mean (s.d.) & $-0.017(0.012)$ & $0.019(0.041)$ & $0.116^{b}(0.038)$ & 0.001 \\
Hemoglobin delta subunit & Mean (s.d.) & $-0.013(0.012)$ & $0.021(0.040)$ & $0.086^{b}(0.037)$ & 0.036 \\
CD163 & Mean (s.d.) & $0.004(0.01)$ & $-0.002(0.034)$ & $0.007(0.031)$ & 0.886 \\
LRP1 & Mean (s.d.) & $0.008(0.019)$ & $-0.077(0.064)$ & $-0.008(0.059)$ & 0.424 \\
\hline
\end{tabular}

ANCOVA models adjusted for age, sex, and APOE\&4 genotype. The mean and standard deviation (s.d.) are presented in the table with false discovery rate correction set at $5 \%$

Units of measurement $=$ a.u

${ }^{\mathrm{a} C \mathrm{~N}}$ vs $\mathrm{MCl}$

${ }^{b} \mathrm{CN}$ vs $A D$

${ }^{\mathrm{C}} \mathrm{MCl}$ vs $\mathrm{AD}$ 


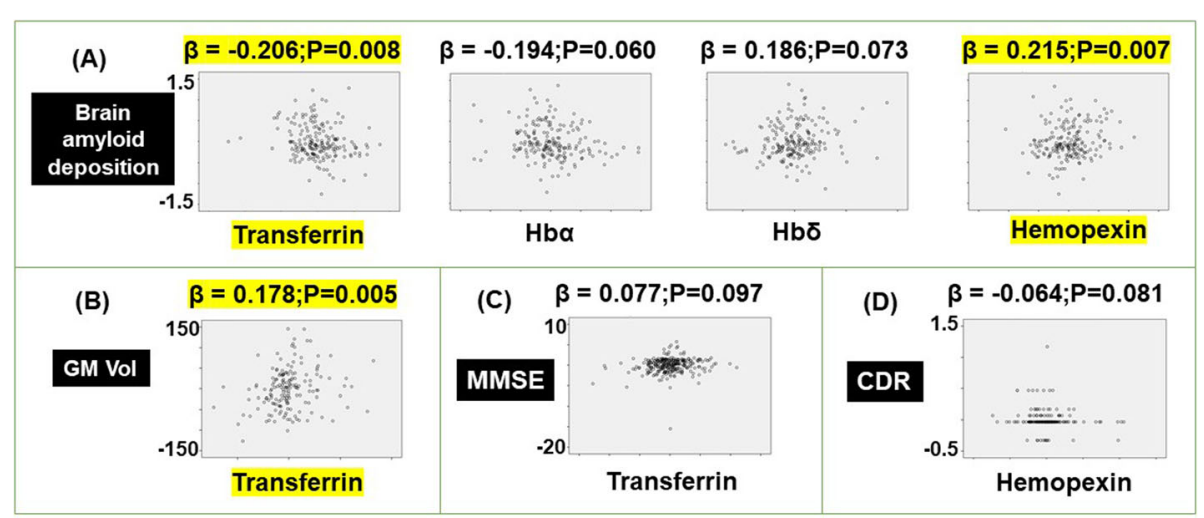

Fig. 1 Modeling the association of plasma ceruloplasmin, transferrin, hemopexin, hemoglobin $(\mathrm{Hb}) \mathrm{a} 1, \mathrm{Hb} \beta, \mathrm{Hb} \delta$, haptoglobin, haptoglobinrelated protein (HPR), cluster of differentiation (CD) 163, and low-density lipoprotein receptor-related protein 1 (LRP1) with a brain amyloid deposition, $\mathbf{b}$ gray matter volume (GM Vol), c mini-mental state examination (MMSE), and $\mathbf{d}$ clinical dementia rating scale (CDR) score, in cognitively normal, mild cognitive impairment, and Alzheimer's disease, in the AIBL cohort. The models included age, sex, APOE 44 genotype, and diagnosis as covariates. The standardized coefficient $(\beta)$ and $p$ values were stated: significant values that survive the false discovery rate correction set at $5 \%$ are highlighted in yellow

Further associations were observed in $\mathrm{CN}$ individuals with stable cognition including higher haptoglobin levels which were associated with augmented levels of hemopexin $\left(r=0.402, p=1.108 \times 10^{-5}\right)$ and CD163 $(r=0.321$, $\left.p=5.565 \times 10^{-4}\right)$. On the contrary, CN subjects showing progression to cognitive impairment showed negative correlation between haptoglobin and CD163 levels $(r=-$ 0.437, $p=0.054$ ) but did not reach significance. Meanwhile, HPR was positively correlated to the hemopexin $\left(r=0.539, p=8.389 \times 10^{-10}\right)$ only in the stable population. Both the $\mathrm{Hb} \beta$ and $\mathrm{Hb} \delta$ subunits were positively associated with hemopexin $(r=0.205, p=0.030 ; r=0.208, p=0.028$ respectively) but did not surpass the FDR-corrected significance threshold. Also, $\mathrm{Hb} \beta$ and $\mathrm{Hb} \delta$ subunits were negatively associated with CD163 only in the stable group $(r=-0.284, p=0.002 ; r=-0.257, p=0.006)$. Hba was associated with $\mathrm{Hb} \beta$ and $\mathrm{Hb} \delta$ in the stable $(r=0.841, p=$ $\left.3.643 \times 10^{-31} ; r=0.839, p=6.994 \times 10^{-31}\right)$ and progression groups $\left(r=0.835, p=4.701 \times 10^{-6} ; r=0.811, p=0.141 \times\right.$ $\left.10^{-5}\right)$. Similarly, $\mathrm{Hb} \beta$ demonstrated significant correlation to $\mathrm{Hb} \delta$ in the stable group $\left(r=0.946,1.218 \times 10^{-55}\right)$ and progression group $\left(r=0.885, p=2.196 \times 10^{-7}\right)$.

\section{Discussion}

AD causes a global disease burden involving failure of neuroprotective mechanisms leading to altered heme/

Table 3 Baseline demographic and clinical characteristics of CN individuals remaining stable and individuals showing progression to cognitive impairment (AIBL cohort)

\begin{tabular}{|c|c|c|c|c|}
\hline & & Stable & Progression & $p$ value \\
\hline$n$ & - & 115 & 23 & NA \\
\hline Age & Years (s.d.) & $72(0.670)$ & $72(1.539)$ & 0.761 \\
\hline Female & $n(\%)$ & $61(53 \%)$ & $9(39 \%)$ & 0.407 \\
\hline APOE- $\varepsilon 4+v e$ & $n(\%)$ & $39(34 \%)$ & $13(57 \%)$ & 0.044 \\
\hline Brain amyloid deposition & PET SUVR (s.d.) & $1.35(0.03)$ & $1.62(0.08)$ & 0.008 \\
\hline MRI hippocampus (right, $\mathrm{cm}^{3}$ ) & Mean (s.d.) & $3.12(0.03)$ & $3.08(0.07)$ & 0.823 \\
\hline MRI hippocampus (left, $\mathrm{cm}^{3}$ ) & Mean (s.d.) & $3.22(0.03)$ & $3.17(0.06)$ & 0.642 \\
\hline MRI gray matter $\left(\mathrm{cm}^{3}\right)$ & Mean (s.d.) & $674(4.69)$ & $668(10.69)$ & 0.633 \\
\hline MRI white matter $\left(\mathrm{cm}^{3}\right)$ & Mean (s.d.) & $436(5.099)$ & $441(11.049)$ & 0.666 \\
\hline MMSE & Mean (s.d.) & $28.895(0.114)$ & $28.127(0.248)$ & 0.006 \\
\hline CDR scores & Mean (s.d.) & $0.024(0.010)$ & $0.021(0.022)$ & 0.893 \\
\hline CDR sum of boxes & Mean (s.d.) & $0.035(0.017)$ & $0.020(0.037)$ & 0.719 \\
\hline
\end{tabular}

ANCOVA models adjusted for age, sex, and APOE\&4 genotype. The mean and standard deviation (s.d.) are presented in the table with false discovery rate correction set at $5 \%$ 
Table 4 Baseline levels of plasma proteins implicated in iron and heme metabolism in CN individuals remaining stable and individuals showing progression to cognitive impairment (AIBL cohort)

\begin{tabular}{lllll}
\hline Plasma proteins & Units & Stable & Progression & $p$ value \\
\hline Ceruloplasmin & Mean (s.d.) & $0.001(0.006)$ & $0.001(0.014)$ & 0.867 \\
Transferrin & Mean (s.d.) & $0.003(0.008)$ & $0.007(0.019)$ & $0.025(0.024)$ \\
Haptoglobin & Mean (s.d.) & $0.005(0.01)$ & $0.036(0.025)$ & 0.458 \\
Haptoglobin-related protein & Mean (s.d.) & $0.003(0.011)$ & $-0.012(0.022)$ & 0.216 \\
Hemopexin & Mean (s.d.) & $0.000(0.010)$ & $0.042(0.036)$ & 0.844 \\
Hemoglobin alpha 1 subunit & Mean (s.d.) & $-0.014(0.016)$ & $0.015(0.037)$ & 0.067 \\
Hemoglobin beta subunit & Mean (s.d.) & $-0.024(0.016)$ & $0.024(0.037)$ & 0.263 \\
Hemoglobin delta subunit & Mean (s.d.) & $-0.020(0.016)$ & $-0.012(0.035)$ & 0.404 \\
CD163 & Mean (s.d.) & $0.009(0.015)$ & $0.028(0.060)$ & 0.901 \\
\hline LRP1 & Mean (s.d.) & $0.007(0.026)$ & &
\end{tabular}

ANCOVA models adjusted for age, sex, and APOE\&4 genotype. The mean and standard deviation (s.d.) are presented in the table with false discovery rate correction set at $5 \%$

Units of measurement $=$ a.u

iron dyshomeostasis and oxidative stress-mediated neurodegeneration [47]. In keeping with the theme of heme dyshomeostasis [48], in this study, we found significantly increased plasma levels of $\mathrm{Hb} \beta$ subunit in $\mathrm{AD}$ compared to $\mathrm{CN}$ individuals. A trend was apparent where lower $\mathrm{Hb} \alpha$ and higher levels of $\mathrm{Hb} \delta$ were associated with increased brain amyloid deposition. How Hb or its metabolites pass the blood-brain barrier remains to be fully understood. It has been posited that increased permeability of the blood-brain barrier early in the disease process may increase $\mathrm{Hb}$ concentration in the brain vasculature and explain the higher prevalence of cerebral amyloid angiopathy in AD [49,50]. Further, increased $\mathrm{Hb}$ in the brains of human and transgenic mouse models of $\mathrm{AD}$ has been suggested to induce astrocytic fatigue, enabling pathogenesis mediated by $A \beta[48,49]$. This is in congruence with our finding of a trend of lower plasma levels of $\mathrm{Hb} \alpha$ associated with increased brain amyloid deposition.

Blood from healthy aged humans (29-51 years) and 8week old young adult mice showed that $\mathrm{Hb} \alpha$ subunits can efficiently remove hydrogen peroxide to prevent

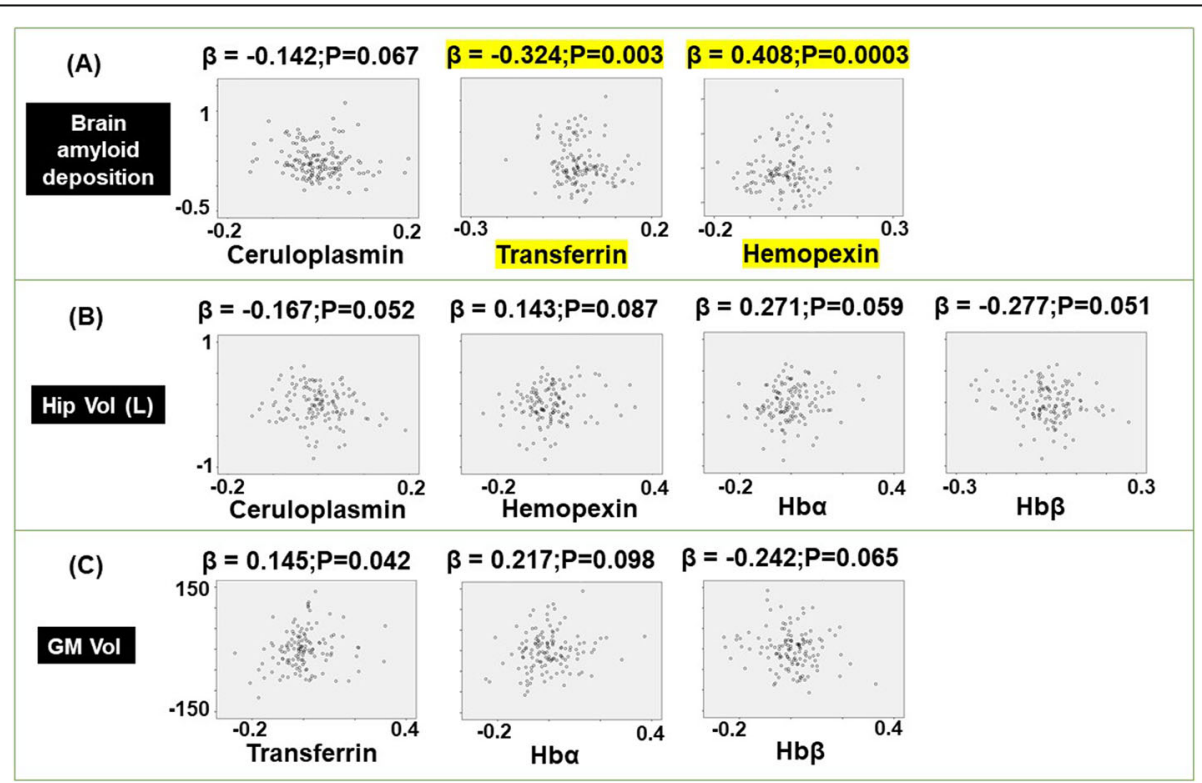

Fig. 2 Modeling the association of plasma ceruloplasmin, transferrin, hemopexin, hemoglobin $(\mathrm{Hb}) \mathrm{a} 1, \mathrm{Hb} \beta, \mathrm{Hb} \delta$, haptoglobin, haptoglobinrelated protein (HPR), cluster of differentiation (CD) 163, and low-density lipoprotein receptor-related protein 1 (LRP1) with a brain amyloid deposition, b left hippocampal volume (Hip Vol (L)), and c gray matter volume (GM Vol) in the AIBL cohort. The models included age, sex, APOE 4 genotype, and conversion status as covariates. The standardized coefficient $(\beta)$ and $p$ values were stated: significant values that survive the false discovery rate correction set at $5 \%$ are highlighted in yellow 


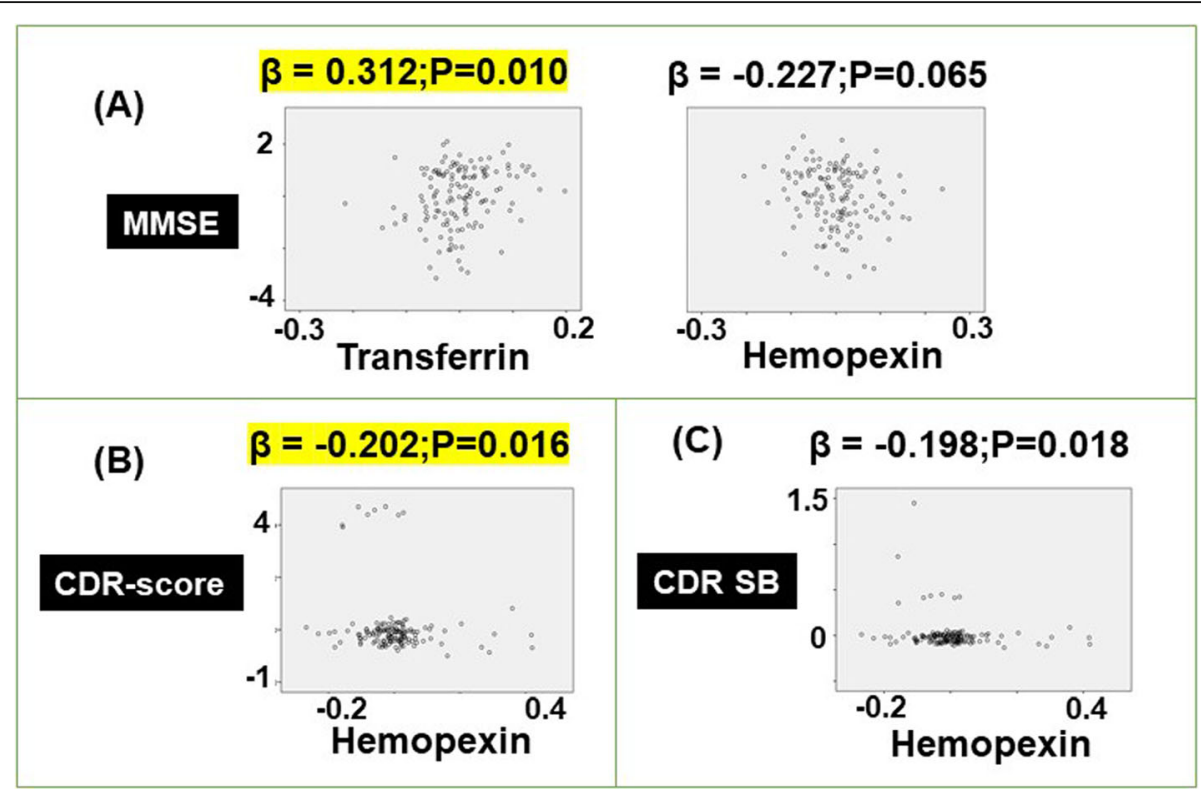

Fig. 3 Modeling the association of plasma ceruloplasmin, transferrin, hemopexin, hemoglobin ( $\mathrm{Hb})$ a1, Hb $\beta, H b \delta$, haptoglobin, haptoglobinrelated protein (HPR), cluster of differentiation (CD) 163, and low-density lipoprotein receptor-related protein 1 (LRP1) with a mini-mental state examination (MMSE), b clinical dementia rating scale (CDR) score, and $\mathbf{c}$ clinical dementia rating sum of boxes (CDR SB), in the AIBL cohort. The models included age, sex, APOE 44 genotype, and diagnosis as covariates. The standardized coefficient $(\beta)$ and $p$ values were stated: significant values that survive the false discovery rate correction set at $5 \%$ are highlighted in yellow

oxidative degradation of $\mathrm{Hb}$, and its ability to scavenge is overtly enhanced in the presence of reduced pyridine nucleotides [20]. Previously, it has been documented that $\mathrm{Hb}$ and heme may help to suppress $\mathrm{A} \beta$-mediated inflammatory activation of astrocytes [49]. Although we report correlation, not causation, the varying association between different subunits leads us to hypothesize that $\mathrm{Hb}$ subunits may modify $\mathrm{A} \beta$-mediated toxicity and ameliorate oxidative stress, probably in divergent ways. This is supported by our finding of an increasing trend

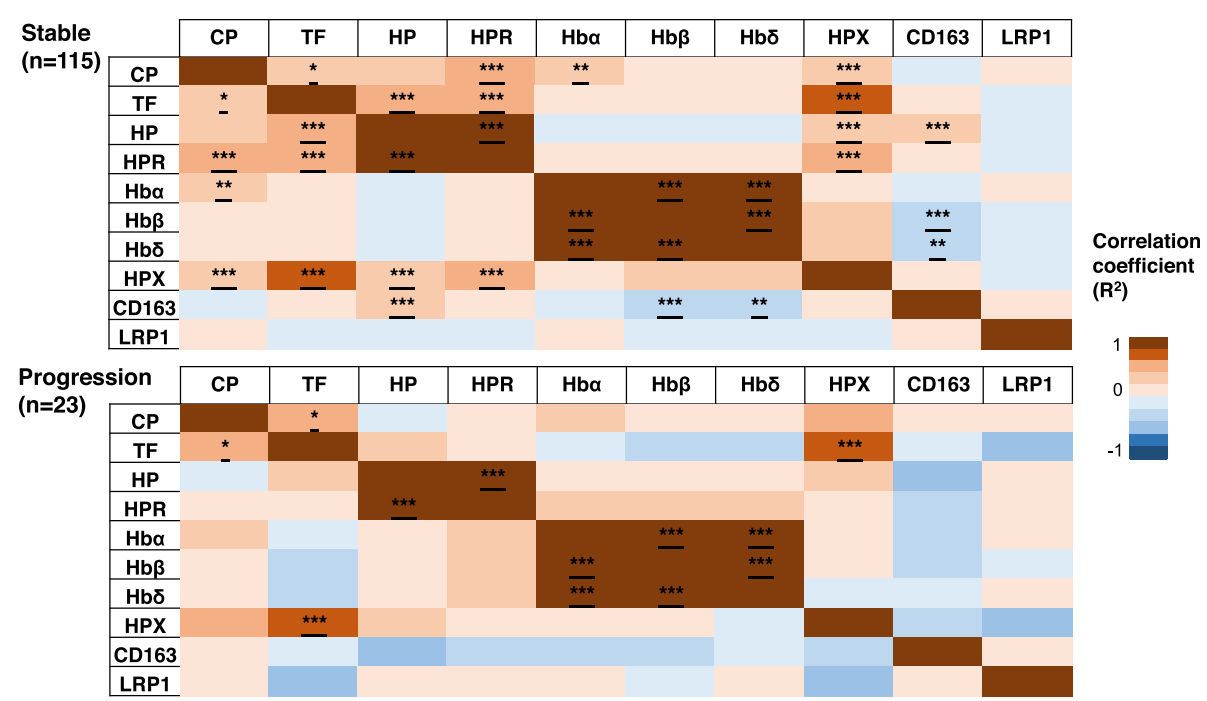

Fig. 4 Partial correlation analysis adjusted for age, sex, and APOE\&4 genotype conducted separately in cognitively normal AIBL individuals remaining stable and showing progression to cognitive impairment. The scale bar represents the correlation coefficient $\left(R^{2}\right)$ and false discovery rate-corrected significance set at $5 \%$ represented by ${ }^{*} p<0.015,{ }^{* *} p<0.009$, and $p<0.005^{* * *}$. Cp, ceruloplasmin; TF, transferrin; HP, haptoglobin; HPR, haptoglobin-related protein; Hb, hemoglobin subunits ( $a, \beta, \delta$ ); HPX, hemopexin; CD163, cluster of differentiation 163; LRP1, low-density lipoprotein receptor-related protein 
of $\mathrm{Hb} \alpha$ associated with increased hippocampal volume in $\mathrm{CN}$ individuals (adjusted for conversion status), but the relationship was found to be the converse for $\mathrm{Hb} \beta$, suggesting perturbations in heme biology is an early event in AD pathogenesis (Fig. 5).

Interestingly, our data showed that increased brain amyloid deposition was associated with higher levels of plasma HPX in the whole cohort, but higher HPX was associated with a lower CDR score in $\mathrm{CN}$ individuals (adjusted for conversion status). HPX co-partners with haptoglobin to bind heme with high affinity and confers protection against free heme-mediated toxicity, maintaining iron homeostasis via recycling of heme iron [28]. HPX knockout mice studies have further substantiated its role as an effective heme/iron scavenger [32]. We observed a significant positive association between HPX and haptoglobin and a trend for $\mathrm{Hb} \beta$ and $\mathrm{Hb \delta}$, only in $\mathrm{CN}$ individuals who remained stable, but this association was absent in those that progressed to cognitive impairment. This suggests that under normal conditions, HPX scavenges and detoxifies heme, but under pathological conditions such as in AD, A $\beta$ disrupts HPX binding to heme through formation of $A \beta$-heme complex, thereby promoting peroxidase activity and accentuating oxidative stress [51-54]. The peroxidase activity of $A \beta$-heme complexes have been shown to induce peptide dimer formation, which in turn enhance $A \beta$ fibrillization [55]. The formation of $\mathrm{A} \beta$-heme complex can decrease heme bioavailability of heme, in effect, inducing functional heme deficiency [51]. The excessive build-up of heme derived from $\mathrm{Hb}$ has been shown to aggravate tau aggregation via the $\mathrm{N}$-terminal free-amines, prolonging peroxidase activity and perpetuating neuronal oxidative stress [56].

Unexpectedly, increased HPX levels correlated with a trend of a decrease in MMSE. However, elevated HPX levels may not reflect increased function as HPX may well be oxidized/inactivated under pathological conditions operant in AD $[57,58]$. The only known HPXheme complex receptor has been identified as LRP1 (also known as CD91), which is expressed in several cell types including macrophages, hepatocytes, neurons, and syncytiotrophoblasts [59] and is responsible for mediating HPX-heme internalization into cells for heme detoxification. We did not observe a significant association between LRP1 and HPX in the CN stable or progression group. However, the role of LRP1 expressing cell types needs to be elucidated alongside putative contribution of alternative receptors for HPX-heme clearance.

Under physiological conditions, haptoglobin binds avidly to $\mathrm{Hb}$ and at macrophages, following binding to its cognate receptor, CD163, the complex is endocytosed, thereby mediating heme and iron homeostasis $[28,60]$. In our dataset, higher levels of haptoglobin were associated with increased levels of CD163 in stable CN individuals but demonstrated a trend of negative association in those showing progression to cognitive impairment. This could imply in the latter $\mathrm{CN}$ individuals, uptake of the haptoglobin-Hb complex by CD163 is inhibited, allowing aberrant heme signaling to increase redox-active iron, which precipitates oxidative stress in $\mathrm{AD}$. The chaperone, haptoglobin, has also been shown to be susceptible to oxidation which hinders its scavenging ability, and in $\mathrm{AD}$,

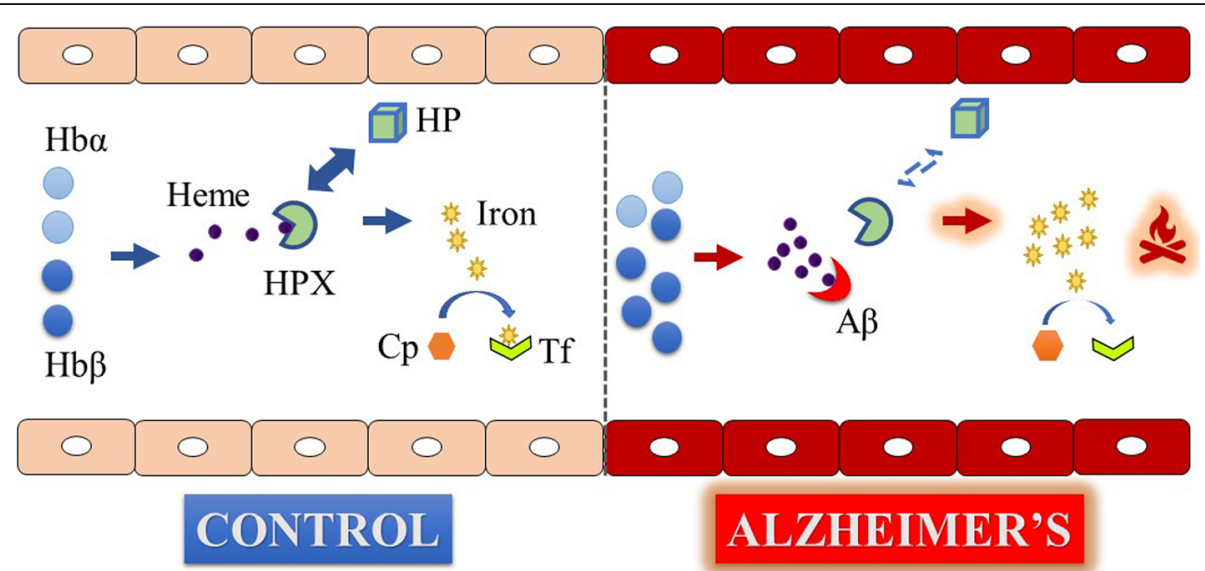

Fig. 5 Schematic to summarize the main findings of the study. Hemoglobin ( $\mathrm{Hb}$ ) a and $\beta$ derived heme is scavenged by hemopexin (HPX) complemented by its co-partner haptoglobin (HP) to form HPX-heme complex. Heme contributes to redox-active iron which is loaded onto transferrin (Tf) with the help of ceruloplasmin ( $\mathrm{Cp}$ ) to maintain iron homeostasis. In the presence of increasing Alzheimer's pathology, augmented levels of $\mathrm{Hb} \beta$ leads to excess free heme, which in the presence of a dissociation between HPX and HP impairs the heme detoxifying system. This enables $\beta$-amyloid $(A \beta)$ to readily form complexes with heme to increase the redox-active iron pool. Since higher levels of $A \beta$ were associated with lower levels of $\mathrm{Tf}$, the ability of $\mathrm{Tf}$ to circulate iron is compromised. The impaired homeostasis of iron leads to enhanced oxidative stress, which contributes to neurodegeneration and progression of Alzheimer's pathology 
enabling $A \beta$ to readily bind heme, further exacerbating $A \beta$-induced toxicity $[61,62]$.

Consistent with previous studies, we did not find significant alterations in plasma transferrin levels in the $\mathrm{CN}$ versus the disease groups. Nevertheless, we demonstrate lower levels of transferrin are associated with augmented brain amyloid uptake. This could particularly be problematic in $\mathrm{AD}$, where deficiency of iron loading into transferrin [7] may enable non-transferrin-bound iron to detrimentally contribute to the labile iron pool, which could help propagate $A \beta$-toxicity. Our finding of increased transferrin levels being associated with increased hippocampal volumes and improved MMSE scores underscores the importance of the role of transferrin to bind iron in a safe and redox-inactive form to distribute elsewhere. The relationship between plasma and brain iron needs to be established; one could hypothesize that the decreases in plasma iron [7,9] is due to increased partitioning of iron into the brain in AD [63]. Macrophages have been suggested to require the ferroxidase activity of ceruloplasmin to load iron onto transferrin. We did not find an increase in ceruloplasmin levels, but ceruloplasmin concentration is not a measure of its activity since oxidation of ceruloplasmin can impair its ferroxidase activity [64] and inhibit iron loading onto transferrin in $\mathrm{AD}$ [8]. One limitation of the study was that we did not investigate protein activities, which could be a useful corollary study. We performed correlation analysis to evaluate the relationship between heme and iron proteins, which does not necessarily equate to causation; hence, future experiments should be directed at identifying causal relationships. In summary, it would be beneficial to understand the expression levels/activity of heme and iron proteins in the plasma, CSF, and tissues of the same subjects to more fully understand heme and iron distributions between various compartments and elucidate the mechanistic interplay.

Perturbed iron homeostasis is a feature of several neurodegenerative diseases including AD, Parkinson's disease, frontotemporal dementia, and amyotrophic lateral sclerosis. We did not study the impact of tau which correlates better with disease progression than $A \beta$ [65] or the contribution of $\alpha$-synuclein, tau, and TDP43 pathologies in the present study, as these pathologies are prevalent in $50 \%$ and $30 \%$ of $\mathrm{AD}$ patients respectively [66]. We predict that these proteins may affect levels of heme and iron proteins, as iron is required for seeding and aggregation of tau [67], of $\alpha$-synuclein [68], and, indirectly, of TDP43 $[69,70]$. We have recently provided evidence to support the presence of a recently discovered iron-dependent cell death, ferroptosis, in AD [71]. Iron chelation has shown promise against $\mathrm{AD}$ and $\mathrm{PD}$ in preclinical studies and clinical trials and has therapeutic potential to extinguish iron-dependent ferroptosis, a mechanism proposed to contribute to neurodegeneration [67]. With relevance to $A D$, longitudinal studies have shown iron burden to be associated with pronounced increase in rate of cognitive decline in $\mathrm{A} \beta$-positive individuals $[63,72,73]$. Moreover, heme/iron accumulation is preferentially observed in $\mathrm{AD}$ affected regions of the brain including parietal cortex, motor cortex, and hippocampus [19, 74-78]. Interestingly, accumulation of tau neurofibrillary tangles is associated with heme oxygenase-1 induction which may further accentuate oxidative stress via release of redox-active iron from heme catabolism [79-81]. We did not perform $\left[{ }^{18} \mathrm{~F}\right]$ FDG-PET to measure glucose metabolism but predict that heme/iron homeostatic proteins would be closely associated with hypometabolism in $\mathrm{AD}$. Whether iron is associated with region-specific effects of neurodegenerative diseases and how it interacts with different pathological proteins/aggregates would be an exciting avenue to explore.

Importantly, heme is derived from $\mathrm{Hb}$, which is enriched in red blood cells [15]. In AD, erythrocytes have been found to contain more surface-bound IgG displaying augmented proteolysis and ensuing oxidative stress, which may trigger their lysis and a subsequent increase in free $\mathrm{Hb}$ fragments $[82,83]$. Together with the reduced heme scavenging potential apparent in $A D$, this may in part explain our finding of increased plasma $\mathrm{Hb} \beta$ in $\mathrm{AD}$ and the varying associations we observed. However, longitudinal studies are warranted to simultaneously temporally stage CSF $\mathrm{Hb}$ during the progression of $\mathrm{AD}$ to understand brain-periphery relationships. Detailed mechanistic studies are required to understand post-translational modifications of $\mathrm{Hb}$ and their associations with $\mathrm{A} \beta$ and tau. Also, different neuronal cell lineages can be transfected to upregulate or downregulate $\mathrm{Hb} \alpha$ and $\mathrm{Hb} \beta$, to test their vulnerability to $A \beta$ and tau toxicity. In transgenic mouse models of $\mathrm{AD}$, cell type-specific (neuron, microglia, and astrocytes) deletions and overexpression of $\mathrm{Hb}$ chains can be performed to assess whether these modifications will alleviate or aggravate the disease burden.

\section{Conclusion}

In conclusion, heme (iron) dyshomeostasis appears to be a feature of $\mathrm{AD}$. The causal relationship between heme/ iron metabolism and $\mathrm{AD}$ warrants further investigation.

\footnotetext{
Abbreviations

AD: Alzheimer's disease; AIBL: Australian Imaging, Biomarker and Lifestyle Flagship Study of Ageing; CDRSB: Clinical dementia rating scale (CDR) and sum of boxes; CD163: Cluster of differentiation 163; CN: Cognitively normal; TE: Echo time; FSE: Fast spin echo; 18F-FBB: Florbetaben; FLAIR: Fluid attenuation inversion recovery; HPR: Haptoglobin-related protein; Hb: Hemoglobin; HPX: Hemopexin; TI: Inversion time; KARVIAH: Kerr Anglican Retirement Village Initiative in Ageing Health; LRP1: Low-density lipoprotein receptor-related protein; $\mathrm{MCl}$ : Mild cognitive impairment; MMSE: Mini-mental state examination; TR: Repetition time; TMT : Tandem mass tag
}

\section{Acknowledgements}

We express our appreciation to all participants in the AIBL and KARVIAH studies. The authors would like to thank BBSRC, King's College London, and Perspectum Diagnostics Ltd., for funding AA's industrial Ph.D. studentship. 


\section{Authors' contributions}

$\mathrm{AA}, \mathrm{NJA}$, and $\mathrm{AH}$ contributed to the study concept and design. AA carried out the data analysis and drafted the manuscript. All authors contributed to the sample selection and data interpretation and revised the manuscript. The authors read and approved the final manuscript.

\section{Funding}

AA is supported by the Biotechnology and Biological Sciences Research Council (BBRSC). N.J.A. was supported by Rosetree Trust for this study. P.C. is supported by KaRa Institute of Neurological Diseases (KaRa MINDS) and Macquarie University. K.G. is funded by Anglicare (Sydney, Australia). R.M. is funded jointly by Edith Cowan University and Macquarie University. A.H. is funded by the Research Centre for Mental Health and Biomedical Research Unit for dementia. PWS is funded by King's College London.

All other authors acknowledge that they received no funding in support of this research.

\section{Availability of data and materials}

All data needed to evaluate the conclusions in the paper are present in the paper. Additional data related to this paper may be requested from the authors.

\section{Ethics approval and consent to participate}

AIBL and KARVIAH were approved by the institutional review board and ethics committees of participating institutions, and written informed consent was obtained from all participants or their next of kin.

\section{Consent for publication}

All authors consented manuscript for publication.

\section{Competing interests}

All other authors declare that they have no competing interests.

\section{Author details}

'Department of Neuroimaging, Institute of Psychiatry, Psychology and Neuroscience, Maurice Wohl Clinical Neuroscience Institute, King's College London, 5, Cutcombe Road, Denmark Hill Campus, London SE5 9RX, UK. ${ }^{2}$ Institute of Psychiatry, Psychology and Neuroscience, Maurice Wohl Institute Clinical Neuroscience Institute, King's College London, London, UK. ${ }^{3} \mathrm{NIHR}$ Biomedical Research Centre for Mental Health and Biomedical Research Unit for Dementia at South London and Maudsley NHS Foundation, London, UK. ${ }^{4}$ Department of Psychiatry and Neurochemistry, The Sahlgrenska Academy at the University of Gothenburg, Mölndal, Sweden. ${ }^{5}$ Wallenberg Centre for Molecular and Translational Medicine, University of Gothenburg, Gothenburg, Sweden. ${ }^{6}$ School of Medical Sciences, Edith Cowan University, 270, Joondalup, WA 6027, Australia. ${ }^{7}$ KaRa Institute of Neurological Diseases, Macquarie Park, NSW, Australia. ${ }^{8}$ Department of Biomedical Sciences, Macquarie University, North Ryde, NSW 2109, Australia. ${ }^{9}$ Clinical Research Department, Anglicare, Sydney, NSW, Australia. ${ }^{10}$ School of Psychiatry and Clinical Neurosciences, University of Western Australia, Crawley, WA, Australia. ${ }^{11}$ Australian E-Health Research Centre, CSIRO, Brisbane, Australia. ${ }^{12}$ Rapiscan Systems, St Leonards, Sydney, Australia. ${ }^{13}$ Academic Unit for Psychiatry of Old Age, St. George's Hospital, University of Melbourne, Victoria, VIC, Australia. ${ }^{14}$ National Ageing Research Institute, Parkville, VIC, Australia. ${ }^{15}$ Department of Molecular Imaging and Therapy, Austin Health, Heidelberg, VIC, Australia.

${ }^{16}$ The Florey Institute, University of Melbourne, Parkville, VIC, Australia.

Received: 5 March 2020 Accepted: 18 May 2020

Published online: 09 June 2020

\section{References}

1. Wortmann M. Dementia: a global health priority - highlights from an ADI and World Health Organization report. Alzheimers Res Ther. 2012;4(5):40

2. Scheltens P, Blennow K, Breteler MM, de Strooper B, Frisoni GB, Salloway S, Van der Flier WM. Alzheimer's disease. Lancet. 2016;388(10043):505-17.

3. Selkoe DJ, Hardy J. The amyloid hypothesis of Alzheimer's disease at 25 years. EMBO Mol Med. 2016;8(6):595-608.

4. Henneman WJ, Sluimer JD, Barnes J, van der Flier WM, Sluimer IC, Fox NC, Scheltens P, Vrenken H, Barkhof F. Hippocampal atrophy rates in Alzheimer disease: added value over whole brain volume measures. Neurology. 2009; 72(11):999-1007.
5. Shah RC, Buchman AS, Wilson RS, Leurgans SE, Bennett DA. Hemoglobin level in older persons and incident Alzheimer disease: prospective cohort analysis. Neurology. 2011;77(3):219-26.

6. Shah RC, Wilson RS, Tang Y, Dong X, Murray A, Bennett DA. Relation of hemoglobin to level of cognitive function in older persons. Neuroepidemiology. 2009;32(1):40-6.

7. Faux NG, Rembach A, Wiley J, Ellis KA, Ames D, Fowler CJ, Martins RN, Pertile KK, Rumble RL, Trounson B, et al. An anemia of Alzheimer's disease. Mol Psychiatry. 2014;19(11):1227-34.

8. Hare DJ, Doecke JD, Faux NG, Rembach A, Volitakis I, Fowler CJ, Grimm R, Doble PA, Cherny RA, Masters CL, et al. Decreased plasma iron in Alzheimer's disease is due to transferrin desaturation. ACS Chem Neurosci. 2015;6(3):398-402.

9. Ashraf A, Stosnach H, Parkes HG, Hye A, Powell J, So PW, AddNeuroMed c: Pattern of altered plasma elemental phosphorus, calcium, zinc, and iron in Alzheimer's disease. Sci Rep 2019, 9(1):3147.

10. Ashraf A, Clark M, So PW. The aging of iron man. Front Aging Neurosci. 2018;10:65.

11. Goozee K, Chatterjee P, James I, Shen K, Sohrabi HR, Asih PR, Dave P, ManYan C, Taddei K, Ayton SJ, et al. Elevated plasma ferritin in elderly individuals with high neocortical amyloid-beta load. Mol Psychiatry. 2018; 23(8):1807-12.

12. Jeong SM, Shin DW, Lee JE, Hyeon JH, Lee J, Kim S. Anemia is associated with incidence of dementia: a national health screening study in Korea involving 37,900 persons. Alzheimers Res Ther. 2017;9(1):94.

13. Tan B, Venketasubramanian N, Vrooman H, Cheng CY, Wong TY, Chen C, Hilal S. Haemoglobin, magnetic resonance imaging markers and cognition: a subsample of population-based study. Alzheimers Res Ther. 2018;10(1):114

14. Biagioli M, Pinto M, Cesselli D, Zaninello M, Lazarevic D, Roncaglia P, Simone $\mathrm{R}$, Vlachouli C, Plessy C, Bertin N, et al. Unexpected expression of alpha- and beta-globin in mesencephalic dopaminergic neurons and glial cells. Proc Natl Acad Sci U S A. 2009;106(36):15454-9.

15. Altinoz MA, Guloksuz S, Schmidt-Kastner R, Kenis G, Ince B, Rutten BPF. Involvement of hemoglobins in the pathophysiology of Alzheimer's disease. Exp Gerontol. 2019;126:110680.

16. Richter F, Meurers BH, Zhu C, Medvedeva VP, Chesselet MF. Neurons express hemoglobin alpha- and beta-chains in rat and human brains. J Comp Neurol. 2009;515(5):538-47.

17. Blalock EM, Chen KC, Sharrow K, Herman JP, Porter NM, Foster TC, Landfield PW. Gene microarrays in hippocampal aging: statistical profiling identifies novel processes correlated with cognitive impairment. J Neurosci. 2003; 23(9):3807-19.

18. Chuang JY, Lee CW, Shih YH, Yang T, Yu L, Kuo YM. Interactions between amyloid-beta and hemoglobin: implications for amyloid plaque formation in Alzheimer's disease. PLoS One. 2012;7(3):e33120.

19. Wu CW, Liao PC, Yu L, Wang ST, Chen ST, Wu CM, Kuo YM. Hemoglobin promotes Abeta oligomer formation and localizes in neurons and amyloid deposits. Neurobiol Dis. 2004;17(3):367-77.

20. Masuoka N, Kodama H, Abe T, Wang DH, Nakano T. Characterization of hydrogen peroxide removal reaction by hemoglobin in the presence of reduced pyridine nucleotides. Biochim Biophys Acta. 2003;1637(1):46-54.

21. Schelshorn DW, Schneider A, Kuschinsky W, Weber D, Kruger C, Dittgen T, Burgers HF, Sabouri F, Gassler N, Bach A, et al. Expression of hemoglobin in rodent neurons. J Cereb Blood Flow Metab. 2009;29(3):585-95.

22. Yang $\mathrm{H}$, Qiao $\mathrm{H}$, Tian X. Proteomic analysis of cerebral synaptosomes isolated from rat model of Alzheimer's disease. Indian J Exp Biol. 2011;49(2):118-24.

23. Brown N, Alkhayer K, Clements R, Singhal N, Gregory R, Azzam S, Li S, Freeman E, McDonough J. Neuronal hemoglobin expression and its relevance to multiple sclerosis neuropathology. J Mol Neurosci. 2016;59(1):1-17.

24. Straub AC, Lohman AW, Billaud M, Johnstone SR, Dwyer ST, Lee MY, Bortz PS, Best AK, Columbus L, Gaston B, et al. Endothelial cell expression of haemoglobin alpha regulates nitric oxide signalling. Nature. 2012;491(7424):473-7.

25. Ferrer I, Gomez A, Carmona M, Huesa G, Porta S, Riera-Codina M, Biagioli M, Gustincich S, Aso E. Neuronal hemoglobin is reduced in Alzheimer's disease, argyrophilic grain disease, Parkinson's disease, and dementia with Lewy bodies. J Alzheimers Dis. 2011;23(3):537-50.

26. Spellman DS, Wildsmith KR, Honigberg LA, Tuefferd M, Baker D, Raghavan N, Nairn AC, Croteau P, Schirm M, Allard R, et al. Development and evaluation of a multiplexed mass spectrometry based assay for measuring candidate peptide biomarkers in Alzheimer's disease neuroimaging initiative (ADNI) CSF. Proteomics Clin Appl. 2015;9(7-8):715-31. 
27. Papanikolaou G, Pantopoulos K. Iron metabolism and toxicity. Toxicol Appl Pharmacol. 2005;202(2):199-211.

28. Smith A, McCulloh RJ. Hemopexin and haptoglobin: allies against heme toxicity from hemoglobin not contenders. Front Physiol. 2015;6:187.

29. Tolosano E, Altruda F. Hemopexin: structure, function, and regulation. DNA Cell Biol. 2002:21(4):297-306.

30. Castano EM, Roher AE, Esh CL, Kokjohn TA, Beach T. Comparative proteomics of cerebrospinal fluid in neuropathologically-confirmed Alzheimer's disease and non-demented elderly subjects. Neurol Res. 2006; 28(2):155-63.

31. Davidsson P, Folkesson S, Christiansson M, Lindbjer M, Dellheden B, Blennow K, Westman-Brinkmalm A. Identification of proteins in human cerebrospinal fluid using liquid-phase isoelectric focusing as a prefractionation step followed by two-dimensional gel electrophoresis and matrix-assisted laser desorption/ionisation mass spectrometry. Rapid Commun Mass Spectrom. 2002;16(22):2083-8.

32. Chen L, Zhang X, Chen-Roetling J, Regan RF. Increased striatal injury and behavioral deficits after intracerebral hemorrhage in hemopexin knockout mice. J Neurosurg. 2011;114(4):1159-67.

33. Ma B, Day JP, Phillips H, Slootsky B, Tolosano E, Dore S. Deletion of the hemopexin or heme oxygenase-2 gene aggravates brain injury following stroma-free hemoglobin-induced intracerebral hemorrhage. J Neuroinflammation. 2016;13:26.

34. Hahl P, Davis T, Washburn C, Rogers JT, Smith A. Mechanisms of neuroprotection by hemopexin: modeling the control of heme and iron homeostasis in brain neurons in inflammatory states. J Neurochem. 2013; 125(1):89-101.

35. Martins RN, Villemagne V, Sohrabi HR, Chatterjee P, Shah TM, Verdile G, Fraser P, Taddei K, Gupta VB, Rainey-Smith SR, et al. Alzheimer's disease: a journey from amyloid peptides and oxidative stress, to biomarker technologies and disease prevention strategies-gains from AIBL and DIAN cohort studies. J Alzheimers Dis. 2018;62(3):965-92.

36. Ellis KA, Bush Al, Darby D, De Fazio D, Foster J, Hudson P, Lautenschlager NT, Lenzo N, Martins RN, Maruff $P$, et al. The Australian Imaging, Biomarkers and Lifestyle (AIBL) study of aging: methodology and baseline characteristics of 1112 individuals recruited for a longitudinal study of Alzheimer's disease. Int Psychogeriatr. 2009;21(4):672-87.

37. Rowe CC, Ellis KA, Rimajova M, Bourgeat P, Pike KE, Jones G, Fripp J, Tochon-Danguy H, Morandeau L, O'Keefe G, et al. Amyloid imaging results from the Australian Imaging, Biomarkers and Lifestyle (AIBL) study of aging. Neurobiol Aging. 2010;31(8):1275-83.

38. Ashton NJ, Nevado-Holgado AJ, Barber IS, Lynham S, Gupta V, Chatterjee P, Goozee K, Hone E, Pedrini S, Blennow K, et al. A plasma protein classifier for predicting amyloid burden for preclinical Alzheimer's disease. Sci Adv. 2019; 5(2):eaau7220.

39. Nasreddine ZS, Phillips NA, Bedirian V, Charbonneau S, Whitehead V, Collin I, Cummings JL, Chertkow H. The Montreal Cognitive Assessment, MoCA: a brief screening tool for mild cognitive impairment. J Am Geriatr Soc. 2005; 53(4):695-9.

40. Petersen RC, Smith GE, Waring SC, Ivnik RJ, Tangalos EG, Kokmen E. Mild cognitive impairment: clinical characterization and outcome. Arch Neurol. 1999;56(3):303-8.

41. Winblad B, Palmer K, Kivipelto M, Jelic V, Fratiglioni L, Wahlund LO, Nordberg A, Backman L, Albert M, Almkvist O, et al. Mild cognitive impairment--beyond controversies, towards a consensus: report of the International Working Group on Mild Cognitive Impairment. J Intern Med. 2004:256(3):240-6.

42. McKhann G, Drachman D, Folstein M, Katzman R, Price D, Stadlan EM Clinical diagnosis of Alzheimer's disease: report of the NINCDS-ADRDA Work Group under the auspices of Department of Health and Human Services Task Force on Alzheimer's Disease. Neurology. 1984;34(7):939-44.

43. Morris JC. The Clinical Dementia Rating (CDR): current version and scoring rules. Neurology. 1993;43(11):2412-4.

44. American Psychiatric A, Task Force on D-I, Frances AA, Pincus HA, First MB: Diagnostic and statistical manual of mental disorders. DMS-IV. DMS-IV. Washington: American Psychiatric Association; 1994.

45. World Health O. The ICD-10 classification of mental and behavioural disorders : diagnostic criteria for research. Geneva: World Health Organization; 2003.

46. Chen JJ, Roberson PK, Schell MJ. The false discovery rate: a key concept in large-scale genetic studies. Cancer Control. 2010;17(1):58-62.
47. Peters DG, Connor JR, Meadowcroft MD. The relationship between iron dyshomeostasis and amyloidogenesis in Alzheimer's disease: two sides of the same coin. Neurobiol Dis. 2015;81:49-65.

48. Atamna H, Frey WH 2nd. A role for heme in Alzheimer's disease: heme binds amyloid beta and has altered metabolism. Proc Natl Acad Sci U S A. 2004;101(30):11153-8.

49. Sankar SB, Donegan RK, Shah KJ, Reddi AR, Wood LB. Heme and hemoglobin suppress amyloid beta-mediated inflammatory activation of mouse astrocytes. J Biol Chem. 2018;293(29):11358-73.

50. Biron KE, Dickstein DL, Gopaul R, Jefferies WA. Amyloid triggers extensive cerebral angiogenesis causing blood brain barrier permeability and hypervascularity in Alzheimer's disease. PLoS One. 2011;6(8):e23789.

51. Atamna H, Boyle K. Amyloid-beta peptide binds with heme to form a peroxidase: relationship to the cytopathologies of Alzheimer's disease. Proc Natl Acad Sci U S A. 2006:103(9):3381-6.

52. Flemmig J, Zamocky M, Alia A. Amyloid beta and free heme: bloody new insights into the pathogenesis of Alzheimer's disease. Neural Regen Res. 2018;13(7):1170-4.

53. Pramanik D, Dey SG. Active site environment of heme-bound amyloid beta peptide associated with Alzheimer's disease. J Am Chem Soc. 2011;133(1): 81-7.

54. Lu N, Li J, Tian R, Peng YY. Key roles of Arg(5), Tyr(10) and his residues in Abeta-heme peroxidase: relevance to Alzheimer's disease. Biochem Biophys Res Commun. 2014;452(3):676-81.

55. Al-Hilaly YK, Williams TL, Stewart-Parker M, Ford L, Skaria E, Cole M, Bucher WG, Morris KL, Sada AA, Thorpe JR, et al. A central role for dityrosine crosslinking of amyloid-beta in Alzheimer's disease. Acta Neuropathol Commun. 2013;1:83

56. Pirota V, Monzani E, Dell'Acqua S, Casella L. Interactions between heme and tau-derived R1 peptides: binding and oxidative reactivity. Dalton Trans. 2016;45(36):14343-51.

57. Hahl P, Hunt R, Bjes ES, Skaff A, Keightley A, Smith A. Identification of oxidative modifications of hemopexin and their predicted physiological relevance. J Biol Chem. 2017;292(33):13658-71.

58. Yu HL, Chertkow HM, Bergman H, Schipper HM. Aberrant profiles of native and oxidized glycoproteins in Alzheimer plasma. Proteomics. 2003;3(11): 2240-8

59. Hvidberg V, Maniecki MB, Jacobsen C, Hojrup P, Moller HJ, Moestrup SK. Identification of the receptor scavenging hemopexin-heme complexes. Blood. 2005;106(7):2572-9.

60. Buehler PW, Abraham B, Vallelian F, Linnemayr C, Pereira CP, Cipollo JF, Jia Y, Mikolajczyk M, Boretti FS, Schoedon G, et al. Haptoglobin preserves the CD163 hemoglobin scavenger pathway by shielding hemoglobin from peroxidative modification. Blood. 2009;113(11):2578-86.

61. Cocciolo A, Di Domenico F, Coccia R, Fiorini A, Cai J, Pierce WM, Mecocci P, Butterfield DA, Perluigi M. Decreased expression and increased oxidation of plasma haptoglobin in Alzheimer disease: insights from redox proteomics. Free Radic Biol Med. 2012;53(10):1868-76.

62. Yerbury JJ, Poon S, Meehan S, Thompson B, Kumita JR, Dobson CM, Wilson MR. The extracellular chaperone clusterin influences amyloid formation and toxicity by interacting with prefibrillar structures. FASEB J. 2007;21(10):2312-22.

63. Ayton S, Wang Y, Diouf I, Schneider JA, Brockman J, Morris MC, Bush Al: Brain iron is associated with accelerated cognitive decline in people with Alzheimer pathology. Mol Psychiatry 2019. https://doi.org/10.1038/s41380019-0375-7.

64. Torsdottir G, Kristinsson J, Snaedal J, Johannesson T. Ceruloplasmin and iron proteins in the serum of patients with Alzheimer's disease. Dement Geriatr Cogn Dis Extra. 2011;1(1):366-71.

65. Braak H, Braak E. Neuropathological stageing of Alzheimer-related changes. Acta Neuropathol. 1991;82(4):239-59.

66. Robinson JL, Lee EB, Xie SX, Rennert L, Suh E, Bredenberg C, Caswell C, Van Deerlin VM, Yan N, Yousef A, et al. Neurodegenerative disease concomitant proteinopathies are prevalent, age-related and APOE4-associated. Brain. 2018;141(7):2181-93.

67. Yamamoto A, Shin RW, Hasegawa K, Naiki H, Sato H, Yoshimasu F, Kitamoto T. Iron (III) induces aggregation of hyperphosphorylated tau and its reduction to iron (II) reverses the aggregation: implications in the formation of neurofibrillary tangles of Alzheimer's disease. J Neurochem. 2002;82(5): 1137-47.

68. Xiao Y, Chen X, Huang S, Li G, Mo M, Zhang L, Chen C, Guo W, Zhou M, Wu $Z$, et al. Iron promotes alpha-synuclein aggregation and transmission by 
inhibiting TFEB-mediated autophagosome-lysosome fusion. J Neurochem. 2018:145(1):34-50

69. Joppe $K$, Roser AE, Maass F, Lingor P. The contribution of iron to protein aggregation disorders in the central nervous system. Front Neurosci. 2019;13:15.

70. Jeong SY, Rathore KI, Schulz K, Ponka P, Arosio P, David S. Dysregulation of iron homeostasis in the CNS contributes to disease progression in a mouse model of amyotrophic lateral sclerosis. J Neurosci. 2009;29(3):610-9.

71. Ashraf A, Jeandriens J, Parkes HG, So PW. Iron dyshomeostasis, lipid peroxidation and perturbed expression of cystine/glutamate antiporter in Alzheimer's disease: evidence of ferroptosis. Redox Biol. 2020;32:101494.

72. Ayton S, Fazlollahi A, Bourgeat P, Raniga P, Ng A, Lim YY, Diouf I, Farquharson $S$, Fripp J, Ames D, et al. Cerebral quantitative susceptibility mapping predicts amyloid-beta-related cognitive decline. Brain. 2017;140(8):2112-9.

73. Du L, Zhao Z, Cui A, Zhu Y, Zhang L, Liu J, Shi S, Fu C, Han X, Gao W, et al. Increased iron deposition on brain quantitative susceptibility mapping correlates with decreased cognitive function in Alzheimer's disease. ACS Chem Neurosci. 2018:9(7):1849-57.

74. Tao Y, Wang Y, Rogers JT, Wang F. Perturbed iron distribution in Alzheimer's disease serum, cerebrospinal fluid, and selected brain regions: a systematic review and meta-analysis. J Alzheimers Dis. 2014;42(2):679-90.

75. Ding B, Chen KM, Ling HW, Sun F, Li X, Wan T, Chai WM, Zhang H, Zhan Y, Guan YJ. Correlation of iron in the hippocampus with MMSE in patients with Alzheimer's disease. J Magn Reson Imaging. 2009;29(4):793-8.

76. Bartzokis G, Sultzer D, Mintz J, Holt LE, Marx P, Phelan CK, Marder SR. In vivo evaluation of brain iron in Alzheimer's disease and normal subjects using MRI. Biol Psychiatry. 1994:35(7):480-7.

77. Luo Z, Zhuang X, Kumar D, Wu X, Yue C, Han C, Lv J. The correlation of hippocampal T2-mapping with neuropsychology test in patients with Alzheimer's disease. PLoS One. 2013;8(9):e76203.

78. Masaldan S, Bush Al, Devos D, Rolland AS, Moreau C. Striking while the iron is hot: iron metabolism and ferroptosis in neurodegeneration. Free Radic Biol Med. 2019;133:221-33.

79. Schipper HM, Bennett DA, Liberman A, Bienias JL, Schneider JA, Kelly J, Arvanitakis Z. Glial heme oxygenase-1 expression in Alzheimer disease and mild cognitive impairment. Neurobiol Aging. 2006;27(2):252-61.

80. Wang D, Hui Y, Peng Y, Tang L, Jin J, He R, Li Y, Zhang S, Li L, Zhou Y, et al. Overexpression of heme oxygenase 1 causes cognitive decline and affects pathways for tauopathy in mice. J Alzheimers Dis. 2015;43(2):519-34.

81. Sripetchwandee J, Wongjaikam S, Krintratun W, Chattipakorn N, Chattipakorn SC. A combination of an iron chelator with an antioxidant effectively diminishes the dendritic loss, tau-hyperphosphorylation, amyloids-beta accumulation and brain mitochondrial dynamic disruption in rats with chronic iron-overload. Neuroscience. 2016;332:191-202.

82. Slemmon JR, Hughes CM, Campbell GA, Flood DG. Increased levels of hemoglobin-derived and other peptides in Alzheimer's disease cerebellum. J Neurosci. 1994;14(4):2225-35.

83. Bosman GJ, Bartholomeus IG, de Man AJ, van Kalmthout PJ, de Grip WJ. Erythrocyte membrane characteristics indicate abnormal cellular aging in patients with Alzheimer's disease. Neurobiol Aging. 1991;12(1):13-8.

\section{Publisher's Note}

Springer Nature remains neutral with regard to jurisdictional claims in published maps and institutional affiliations.

Ready to submit your research? Choose BMC and benefit from:

- fast, convenient online submission

- thorough peer review by experienced researchers in your field

- rapid publication on acceptance

- support for research data, including large and complex data types

- gold Open Access which fosters wider collaboration and increased citations

- maximum visibility for your research: over $100 \mathrm{M}$ website views per year

At BMC, research is always in progress.

Learn more biomedcentral.com/submissions 